\title{
COSAS DE LOS CIENTÍFICOS
}

\section{THINGS OF SCIENTISTS}

José Antonio Martínez Pons: Departamento de Química Analítica e Ingeniería Química. Universidad de Alcalá de Henares. Madrid (España) joseantonio.martines@uah.es

\section{CURRÍCULUM VITAE}

Licenciado en Ciencias Físicas (Geofísica) por la Universidad Complutense de Madrid (España) y en Ciencias Químicas (Química física) por la UNED (España). Doctor por la Universidad de Alcalá de Henares (España) en el año 2000. Profesor de la Universidad de Alcalá de Henares en el área de Química analítica e Ingeniería química.

\section{RESUMEN}

La mayoría de grandes científicos han hecho sus descubrimientos clave jóvenes, valgan como paradigma Newton y Heisenberg, pero no hay regla sin excepción y André Marie Ampère lo fue. No todos los científicos se distinguen por su buen humor y buenas formas. Los científicos son seres humanos con sus vicios y sus virtudes, y el mal carácter abunda entre ellos. Como la envidia y los celos. Vamos a ver una serie de ejemplos. 


\title{
PALABRAS CLAVE
}

Científicos - Descubrimientos - Paradigmas

\begin{abstract}
Most great scientists have made key discoveries youth, as a paradigm worth Newton and Heisenberg, but there is no rule without exception, André Marie Ampère was. Not all scientists are known for their good humor and good manners. Scientists are human beings with their vices and virtues, and bad temper rife among them. As envy and jealousy. We will see a series of examples.
\end{abstract}

\section{KEY WORDS}

Scientists - Discoveries - Paradigms

TEXTO:

La mayoría de grandes científicos han hecho sus descubrimientos clave jóvenes, valgan como paradigma Newton y Heisenberg, pero no hay regla sin excepción y André Marie Ampère lo fue; de hecho, si se hubiera muerto a los cincuenta años hoy no se hablaría para nada de él. 

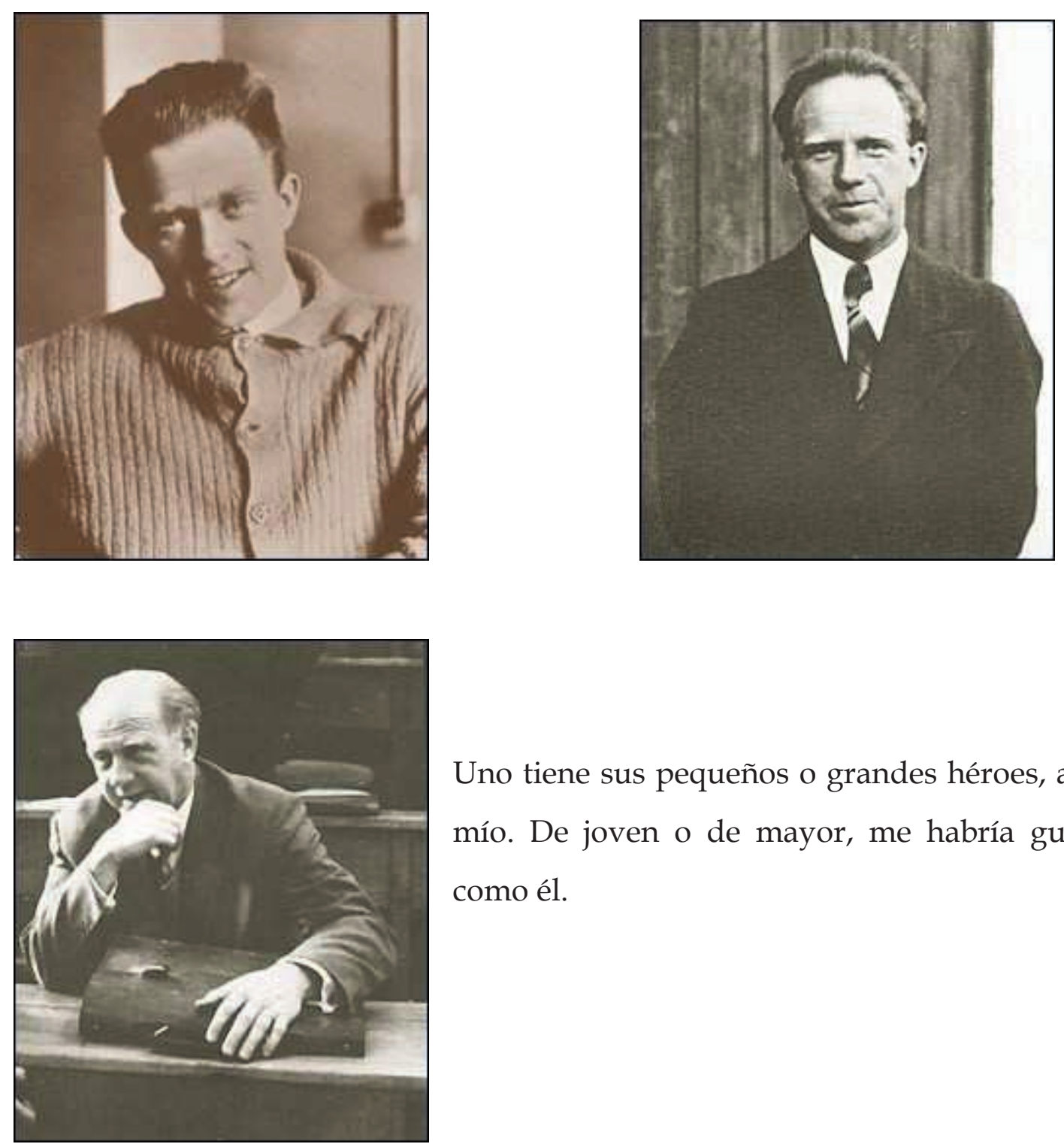

Uno tiene sus pequeños o grandes héroes, ahí está el mío. De joven o de mayor, me habría gustado ser como él.

Tampoco realizaron sus obras maestras de jóvenes ni Cervantes, don Miguel, ni Brahms Herr Johannes, al menos en lo que se refiere a sinfonías... iy qué cuatro sinfonías nos dejó!, menos mal que empezó tarde.

Monsieur le professeur, además, poseía una de las características de todo científico que se precie, el despiste en grado sumo: Una vez el Emperador Napoleón visitó el centro donde Ampère trabajaba 
- Sabe Vd. quien soy yo.

- Pues no señor, no tengo ese gusto.

- Pues soy el Emperador.

- Pues encantado de conoceros.

- Vd. y yo debemos ser amigos y los amigos deben conocerse bien, así que venga tal día a cenar conmigo en Las Tullerías...

Y Ampère se olvidó y no fue.

Otra vez, cuando entraba en la Universidad, en la puerta había un carromato pintado de negro. Ampère se creyó que era la pizarra de su aula, sacó un pedazo de tiza del bolsillo de su levita y empezó a explicar su lección. El problema es que el carretero no se dio cuenta $\mathrm{y}$, arre, puso en marcha el vehículo y ahí tenemos a Ampère persiguiendo la "pizarra" tiza en ristre.

Claro que la excentricidad no sólo es cosa de latinos.

El gran Niels Bohr era un hombre muy inteligente pero muy lento, le costaba llegar a las cosas pero cuando llegaba era un carro blindado. En las veladas con sus alumnos gustaba de resolver crucigramas, muchas veces no se le ocurría una determinada palabra, la consultaba en voz alta. Si nadie le respondía, ahí quedaba, pero su cerebro no paraba, así que, tal vez, a las cuatro o las cinco de la mañana (hora de Copenhague) se le ocurría, entonces era capaz de despertar a quien había hecho la pregunta. Otras veces, también en las largas tardes danesas, solía decir "Hay que hacer algo" y entonces se iba con algunos de sus colaboradores al cine, a ver una del 
Oeste. Normalmente no se enteraba del argumento al inicio, de modo que, a lo mejor, su cerebro acababa de procesar las cosas cuando la película estaba bien avanzada y entonces empezaba a comentar en voz alta a sus acompañantes entre siseos y protestas del respetable.

Otra vez, ya mayor, paseaba por los jardines de su Universidad con un joven físico que además era escalador.

- ¿Y entonces usted se divierte trepando por la pared de las rocas?

- Pues si profesor.

- ¿Y no será muy diferente que trepar por una pared de una casa, como aquella?

- Pues no.

- ¿Y usted cree que yo podría intentarlo?

- Todo es proponérselo...

Y ni corto ni perezoso Bohr se lanzó a escalar la pared de uno de los edificios de Campus. Lo mejor fue que llegaron dos policías a todo correr pensando que se trataba de un "caco" vulgar y corriente. Menos mal que ahí estaba el escalador.

- Ah, bueno, cosas del profesor Bohr -y se fueron.

Después de la II Guerra, Bohr había hecho algunas declaraciones pacifistas, de modo que Stalin pensó en atraérselo a su causa -el comunismo estalinista siempre se presentó como paladín de la Paz entre los pueblos-, así que decidió enviar a dos 
agentes para que le entrevistaran, uno era un joven físico, especialista en meteorología y el otro el consabido agente del KGB. Hablaron con Bohr y no enteraron de nada de lo que les contó, de modo que el resultado de la entrevista se fraguó en la habitación del hotel donde se hospedaban los Tovarich, más de acuerdo con lo que Stalin quería oír que con lo que Bohr quiso decir. Bohr nunca se tomó la molestia de hacerles rectificar.

No todos los científicos se distinguen por su buen humor y buenas formas. Los científicos son seres humanos con sus vicios y sus virtudes, y el mal carácter abunda entre ellos. Como la envidia y los celos.

De Newton se dice que, cuando preparaba una disputa, escribía y corregía los insultos e invectivas que iba a dirigir a su adversario. Desde luego Sir Isaac no pasará a la historia por su bondad personal. Parece ser que, cuando fue director de la casa de la Moneda inglesa, se vanagloriaba de que durante su mandato se había ahorcado a más gente que nunca por monedero falso. En cambio su compatriota Michael Faraday era la otra cara del espejo. Pertenecía a una secta protestante, la de los sandemanianos, que se caracterizaba por una observancia ad pedem literae de la Biblia. El finísimo y escéptico Faraday en cosas científicas, aceptaba sin discusión lo que se decía en el Libro. Pues bien. Su Graciosa Majestad la Reina Victoria le condecoró con una cierta distinción del Imperio Británico. Faraday tuvo la debilidad de aceptarla y fue expulsado de su Iglesia por vanidoso. Sólo después de seis meses de penitencia pública fue aceptado de nuevo.

Otra muestra del modo de ser de Faraday es que, cuando su país, Inglaterra, estaba envuelta en la Guerra de Crimea - la que dio origen a la célebre película "La carga de Brigada Ligera"-, recibió un encargo del Gobierno de Su Majestad sobre la posibilidad de preparar gases asfixiantes como arma de guerra. Faraday informó que 
era posible pero no los preparó. Todo lo contrario de lo que hizo Fritz Haber de quién hablaré, si ha lugar, en alguna ocasión.

Siguiendo con el mal carácter, tal vez la medalla de oro corresponda al Físico Wolgang Pauli, uno de los genios de la Física Teórica. Era implacable con sus propios colegas. Tanto es así que en el mundillo de los físicos era conocido, y a él parece que no le molestaba, como el "azote de Dios". Una de sus calificaciones, o descalificaciones, que han pasado a la historia es la de "ni siquiera falso". Claro que compensaba su agudeza teórica siendo un auténtico desastre en el mundo práctico. De "gafe" se le habría calificado en España. Más de un compañero experimental no le dejaba entrar en su laboratorio y, si era preciso consultar algo con él, -entonces todavía no se había inventado el "móvil"-, lo hacía a través de la puerta, por supuesto cerrada.

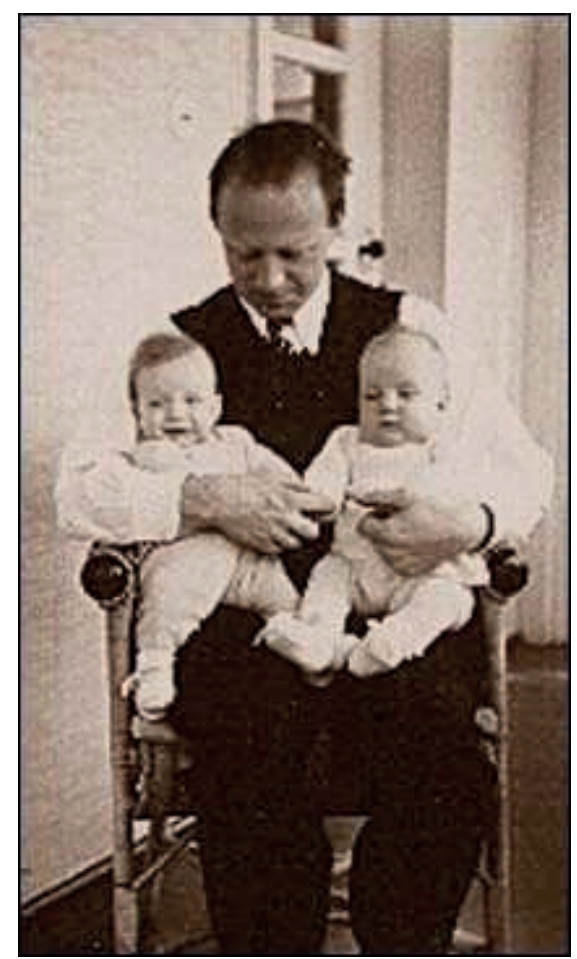

Papá Werner y el par de partículas 


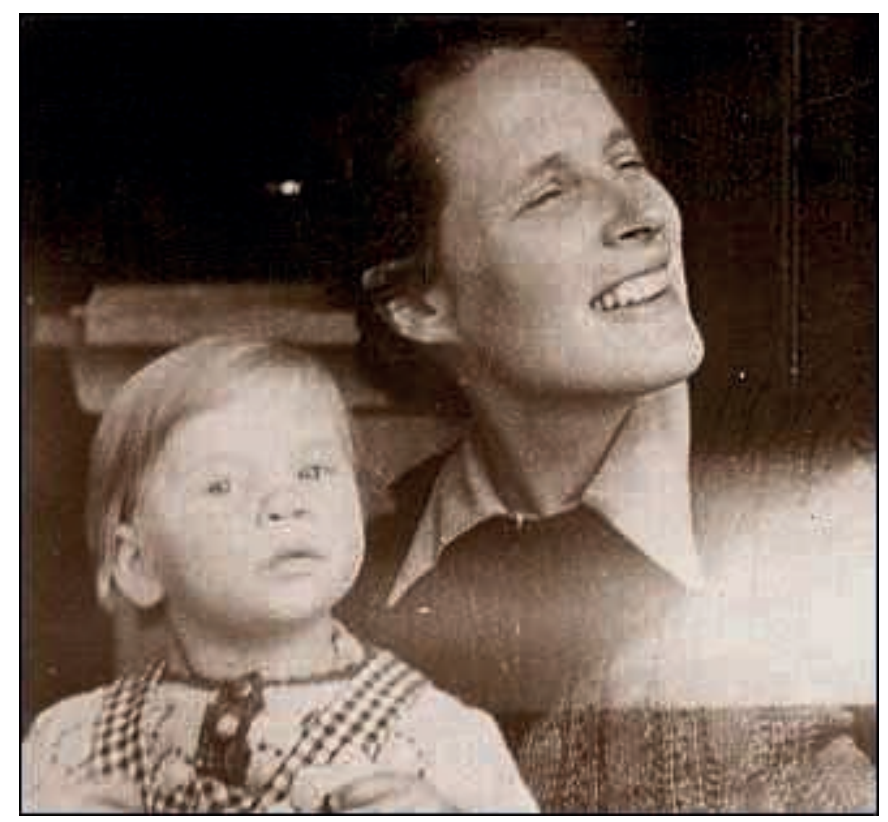

Elisabeth Heisenberg y otro electrón desapareado de la familia

El nivel de maleficio que inducía se refleja en la siguiente anécdota:

Pauli hacía frecuentes viajes en tren desde Zurich, donde trabaja, hasta Copenhague, donde trabaja su amigo Bohr. El tren pasaba por la ciudad alemana de Heildelberg. Se cuenta que, una vez, en el departamento de Física de la famosa universidad de esa ciudad, se estaba realizando un delicado experimento de física de partículas. De repente y sin que hubiera motivo aparente, el dispositivo experimental se vino abajo. Nadie encontraba razón, hasta que a alguno de los científicos se le ocurrió mirar su reloj y comprobar que, precisamente a la hora en que ocurrió la catástrofe, el tren de Pauli hacia 5 minutos de parada en la estación de Heildelberg. Todo un caso de transmisión de maleficio a distancia o de teletrasporte y entrelazamiento de partículas, "avant la lettre" por seguir en el campo de la mecánica cuántica.

Sin embargo, a veces, tenía algún rasgo de humor. Cuando se enteró de que Heisenberg, a pesar del chascarrillo, se había casado con una guapa mujer,- experta en literatura, Elisabeth Schumacher, con la que tuvo nada menos que siete hijos, de 
modo que supo encontrar tanto el momento como la posición oportunos,- y había tenido sus primeros hijos, un par de mellizos, Wofgang y Maria, le felicitó muy efusivamente por su creación de "un par". No sé si añadió con espines opuestos, aunque era capaz.

Antes hablé de la lentitud cerebral de Bohr, otros científicos son todo lo contrario, por ejemplo se cuenta de Von Neumann -¿físico o matemático?-, que en una fiesta un periodista le propuso el siguiente problema:

"Dos ciclistas pedalean una al encuentro de otro a $20 \mathrm{~km} / \mathrm{h}$ por una carretera recta, una mosca que vuela a $50 \mathrm{~km} / \mathrm{h}$ va desde la nariz de uno de los ciclistas a la del otro y viceversa. Desde que la mosca empieza su recorrido hasta que los ciclistas se encuentran trascurre media hora. ¿Qué distancia ha recorrido la mosca?"

Von Neumann casi sin pensar respondió:

- Veinticinco kilómetros.

- Caramba dijo el periodista, pensé que los científicos eran mucho más complicados y que usted habría sumado una serie infinita.

- ¿Es que hay otro modo? -respondió Von Neumann

(Nota: el periodista pensó que Von Neuman, como la mayoría de mortales, había razonado de modo simple: si la mosca está volando a $50 \mathrm{~km} / \mathrm{h}$ durante media hora, ha recorrido $25 \mathrm{~km}$, dicho sea con perdón y permiso de Zenón, pero Von Numann no era como la mayoría de los mortales y había planteado y sumado la serie en el mismo tiempo que un simple mortal divide por dos) 
Por cierto, ya que hablé de Zenón... Como es bien sabido Zenón afirmaba que el movimiento no existía y lo probaba con sus "aporías", ejemplos que, en síntesis, consisten en descomponer el movimiento en una serie de infinitos instantes, más o menos estáticos. Este era su argumento básico, sin comprender que una serie de este tipo puede converger a un valor finito, faltaba más de una docena de siglos para que aparecieran, Newton, Leibnitz y demás padres del cálculo infinitesimal.

Cuando se le intentaba demostrar experimentalmente que el movimiento existía, simplemente andando, solía responder que se trataba de ilusiones de los sentidos, que nos engañan y ponía el ejemplo de la sensación que se siente si se sumerge una mano en agua caliente y otra en fría y después las dos en tibia.

Se cuenta que yendo con sus alumnos por la calle explicándoles sus teorías, apareció un perro rabioso. Zenón sin pensárselo demasiado, se recogió la clámide y echó a correr.

- ¿Por qué corres maestro, si puesto que el moviendo no existe, el perro jamás te alcanzará como Aquiles el atleta jamás alcanza a la tortuga?

- Ya lo sé querido discípulo, pero me producirá la ilusión de que me alcanza y ésta es una ilusión muy desagradable que quiero evitarme. 